\title{
Anterior Crowns in Pediatric Dentistry: A Review
}

\author{
Sneha Shrestha, ${ }^{1}$ Bandana Koirala,${ }^{2}$ Mamta Dali,${ }^{3}$ Gajendra Birajee ${ }^{4}$ \\ ${ }^{1}$ Assistant Professor, ${ }^{2}$ Professor, ${ }^{3}$ Associate Professor, ${ }^{4}$ Assistant Professor, \\ Department of Pedodontics and Preventive Dentistry, B.P. Koirala Institute of Health Sciences, Dharan, Nepal.
}

\begin{abstract}
Anterior crowns have undoubtedly become one of the best discoveries in the field of pediatric dentistry today. There is a wide variation in the parental demand, availability and usage of pediatric anterior crowns worldwide. With the availability of a variety of anterior crowns in the market for children, the choice of selection is a question at hand for all the pediatric dentists. Continued update about these crowns will enhance our understanding about the topic and facilitate promotion of good clinical practice. Hence this review intends to highlight on all the anterior pediatric crowns available along with their recent advances. Evidence was collected via systematic searches through electronic databases, Pubmed and Google scholar.
\end{abstract}

Keywords: Anterior crowns, children, esthetics, pediatric crown.

\section{INTRODUCTION}

Traditionally, carious primary anterior teeth in children were preferred to be left for natural shedding or extraction, if symptomatic. Lately, the demand for saving such teeth is on rise, the major reasons being attributed to increasing awareness on children's oral health and perceived need for oral esthetics by the society. ${ }^{1}$ Anterior pediatric crowns are full coverage restorations, prefabricated or custommade forms that are cemented or bonded to the teeth. These should serve as interim restorations with adequate esthetics, durability and retention till the primary teeth remain in the oral cavity thereby facilitating for holistic growth. ${ }^{2}$ The most common reason for full coverage restoration of primary anterior teeth has been found to be early childhood caries, usually seen in 18 to 36 month-old children. Full coronal restoration of primary anterior teeth may be indicated in conditions such as: multisurface caries, incisal edge involvement, extensive cervical decalcification, non-vital teeth, poor oral hygiene, incisors with large single surface restorations, precision preparations difficult to achieve due to uncooperative behavior. $^{3}$

\section{Correspondence}

\section{Dr. Sneha Shrestha}

Assistant Professor, Department of Pedodontics and

Preventive Dentistry, BPKIHS, Dharan, Nepal

E-mail: snehastha3@gmail.com

\section{Citation}

Shrestha S, Koirala B, Dali M, Birajee G. Anterior Crowns in Pediatric Dentistry: A Review. J Nepalese Assoc Pediatr Dent. 2020;1(1):32-8.
Providing qualitative full coverage restorations to children have always been a matter of great concern to pediatric dentists due to the factors such as child behavioral issues, limited availability of the required size and shades of these crowns, cost and primary tooth morphological factors. ${ }^{4}$ In recent years, pediatric dentistry has seen the emergence of variety of full coverage anterior crowns with each having their own advantages and disadvantages. With strip crowns being cherry-picked for quite a time, popularity for preveneered stainless steel crowns (PVSSCs), and lately zirconia crowns are on rise these days. However, crowns for lower anterior teeth are offered by only the recent additions such as Zirconia crowns, Pediatric Edelweiss crowns and Figaro crowns. ${ }^{3,5}$ Strong clinical data on these crowns are scarce. ${ }^{3}$ This review intends to highlight on all the anterior pediatric crowns available along with their recent advances.

Various classifications of anterior crowns are available in the literature based on their methods of cementation and material composition (Figure. 1).,2,36

\section{GEMENTED CROWNS}

\section{STAINLESS STEEL GROWN (SSC)}

Stainless steel crowns are the easiest and the most durable, retentive, full coverage restorations available for pediatric patients. ${ }^{4,6-9}$ These were introduced by the Rocky Mountain Company in 1947 and popularized by W. P. Humphrey in $1950 .^{2}$ These restorations provide excellent support for severely carious and fractured primary anterior teeth in a cost-effective way. However, they are least preferred for anterior restorations due to their unaesthetic metallic appearance. ${ }^{7}$ 


\section{Cemented/luted}

1. Stainless steel crown

2. Stainless steel crown with facings

A. Facial cut out SSC

B. Preveneered or resin veneered SSC
a. Cheng crowns
b. Kinder Krowns
c. NuSmile crowns
d. Whiter Biter crowns II
e. Pedo Compu crowns
f. Dura crowns
g. Flex crowns

3. Aluminium veneered tooth colored material crowns

- Pedo pearls

- Java crowns

4. High density polyethylene crowns

5. Pedo natural crowns

6. Acrylic crowns

7. Zirconia crowns

8. Composite based crowns

- Figaro crowns

\section{Bonded}

1. Polycarbonate crowns

2. Strip crowns

3. Pedo jacket crowns

4. Composite based crowns

- Preformed

o New Millennium crowns

o Artglass/Glastech crowns

o Pediatric Edelweiss crowns

- Lab enhanced customized

- Indirect custom made composite resin/shell crowns

5. Biologic crowns
1. Polymer crowns

- Polycarbonate crowns

- Strip crowns

- Pedo jacket crowns

- Pedo natural crowns

- Acrylic crowns

- Composite based crowns

o New Millennium crowns

o Artglass crowns

o Figaro crowns

o Pediatric Edelweiss crowns

o Lab enhanced customized

o Indirect custom made composite resin/shell crowns

2. Preveneered SSCs

3. Zirconia crowns

4. Aluminium veneered tooth colored material crowns

Figure 1. Classification of Anterior Crowns in Pediatric Dentistry.

\section{MODIFICATIONS OF SSC}

Various modifications of SSC that provide better esthetics along with the strength and durability of SSC are available in the market. ${ }^{4}$ However, retention of facial esthetic veneers holds a major concern with these modifications.

\section{FAGIAL GUT OUT STAINLESS STEEL GROWN (OPEN FACED SSC)}

It was introduced by Hartmann in $1983 .{ }^{10}$ This full coverage restoration is shaped by a chair side veneering technique in which esthetic facing of composite or glass ionomer cement (GIC) is placed in the prepared labial cavity of the crown after its placement. These restorations are not much desired in terms of esthetics due to the decaying qualities of facings and strength along with the visible cervical metal margins, not to forget their complicated manipulation. , $, 6,7,9-12$ The use of glass ionomer facings exhibited more micro leakage than the composite facings regardless of the length of aging., ${ }^{4,7}$ This technique is otherwise considered successful in restoring the function and esthetics of severely damaged anterior teeth and those which might require frequent pulpal procedures. ${ }^{10}$

\section{PREVENEERED STAINLESS STEEL CROWN (PVSSC)}

PVSSCs came into limelight in the mid-1990s and are likely the most widely used esthetic anterior restorations today. ${ }^{13}$ These are preformed crowns that can be inserted in a single appointment and offering the durability of SSC with esthetics of resin facing. ${ }^{9,12}$ Although they are less sensitive to moisture contamination, few drawbacks with these relatively inflexible crowns are their limited availability in varying sizes and shades, need for greater removal of tooth structure owing to its limited crimpability, veneer loss with time and also the high cost. ${ }^{3,9,10,13}$ Difficulty in placing multiple approximating crowns in areas of crowding or space loss have also been reported with these crowns. For 
most of these crowns, heat sterilization has been found to degrade the bond strength and color stability., ${ }^{4,67}$ Various commercially available PVSSCs are listed below:

i. Cheng Crowns Classic were developed in 1987 as world's first esthetic pediatric crown. They come with thin pre-contoured veneers over SSC and offer exclusive retentive pre-crimping. The high quality composite facings of these crowns provide color stability and plaque resistance. In addition, these can undergo heat sterilization without significant effect on their bond strength and color. These are available in suitable pedo-shades and in six sizes each for upper left and right incisors, and upper and lower cuspids. ${ }^{4,6,10}$

ii. Pre-veneered Kinder Krowns ${ }^{\circledR}$ were introduced in 1989 with the IncisaLock internal design modification that offered better bonding and mechanical retention to the tooth crowned. These natural looking crowns are faced with high quality composite ${ }^{10,14}$ and are available in contoured or universal styles with regular and short lengths. ${ }^{14}$ These are available in two shades of Pedo 1 and 2 in bleached white and in most natural shade, respectively with reported lower failure rate and good parental satisfaction. ${ }^{2,6,15}$

iii. Dura Crowns presented another facet to pediatric esthetic anterior crowns with tooth colored high density polyethylene facing over SSC. These crowns can be compressed, shortened and crimped both labially and lingually. In addition, Dura crowns are available in a single shade with full knife-edged margins and offer ease in festooning and trimming with scissors. ${ }^{2,6,10}$

iv. NuSmile Signature Crowns are another notable addition to PVSSCs since 1991 and have become most popular among both the dentists and parents anon. These crowns efficiently restore correct anatomy with the available two sizes of regular and short in universal styles, providing excellent esthetics and durability. In addition, heat sterilization does not have any significant effect on their bond strength and color. These full coverage restorations have been found to be clinically successful for anterior primary teeth with severe decay. ${ }^{10}$ Gupta et al. concluded that veneer resistance to fracture for NuSmile crimped crowns was comparable to non-crimped crowns. ${ }^{16}$ However, caution should be taken while crimping the lingual aspect of these crowns for the risk of facial veneer fracture. ${ }^{10}$ Guelmann et al. reported the retention of NuSmile crowns, Dura crowns and Kinder Krowns were significantly higher than the non-veneered ones, when crimped and cemented together. ${ }^{17} \mathrm{~A}$ study by Oueis $\mathrm{H}$ et al. in 2010 also reported that $51 \%$ of the pediatric dentists utilized PVSSCs amongst which, NuSmile crowns (61\%) took the forefront followed by Kinder Krowns (35\%) and Cheng crowns (28\%). ${ }^{13}$

v. Whiter Biter Crowns have polymeric coating with a polyester/epoxy hybrid composition. These crowns are however no longer used now. ${ }^{2,10}$

vi. Pedo Compu Crowns are anterior SSC with high quality composite facing. They are color stable and plaque resistant. ${ }^{2,6,9,10}$

vii. Flex Growns are new overall white faced pediatric crowns that can be crimped on facial and lingual and can also be squeezed onto the mesial and distal to allow for better adaptation. These can be trimmed easily with scissors or green stone..$^{10,18}$

\section{ALUMINIUM VENEERED WITH TOOTH- COLORED MATERIAL GROWNS}

These crowns are available as Pedo Pearls and Java crowns in the market. No available published article could be found for Java crowns.

\section{PEDO PEARLS}

Pedo Pearls are tooth colored crowns that are clinically easy to be placed amongst all the esthetics crowns, but possess less durability. ${ }^{6}$ Introduced in 1980, these soft, flexible aluminium crowns are available in universal anatomy with tooth colored epoxy paint coating. They require minimum tooth reduction and can be easily crimped with no risk of chipping. However, the coating tends to chip off in areas of heavy occlusion and in bruxers that can be easily repaired with composite. .,4,6,10,19 $^{-1}$

\section{HIGH DENSITY POLYETHYLENE VENEERED GROWNS}

These crowns are esthetic preformed crowns which are veneered with high density polyethylene that is thermoformed over a screened preformed stainless steel crown to obtain the desired appearance. Advantages include natural appearance, high elasticity and flexural strength with no chipping, crazing or splitting. These adapt to the tooth by mechanical retention and does not disengage easily. ${ }^{9,10,20}$

\section{PEDO NATURAL GROWNS}

Pedo natural crowns are unique ultra-thin and flexible polycarbonate crowns that can be crimped and cemented onto the teeth without much issue of isolation. They were 
introduced in 1997 and offer durability with high tensile strength. ${ }^{2,45}$ These crowns require acrylic filling before luting with translucent cement shade of GIC or selfadhesive resin cements. Unlike stainless steel or veneered crowns, they can be easily placed over teeth with mesiodistal dimension loss, in crowded arch as well as in Class III malocclusions. However, these require greater tooth reduction and also are not recommended in patients with heavy bruxism.

\section{BONDED CROWNS}

\section{POLYGARBONATE GROWNS}

Polycarbonate crowns are one of the earliest crowns introduced in pediatric dentistry. These were first introduced and described in the literature by Mink J.W in 1973. ${ }^{4}$ The original version of these crowns are rarely used today mainly due to its poor retention. Polycarbonate crowns are preformed, heat-molded, tooth colored/ translucent acrylic resin shells possessing high impact strength and rigidity. ${ }^{6,7,9,10}$ The placement technique involves self-cure acrylic resin liner that ensures chemical bond to the crown and good marginal adaptation followed by composite cementation. Slight mechanical roughening on the inner aspect of crown promotes better bonding to composites. ${ }^{10}$ Polycarbonate crowns are crimpable and easy to trim but common problems such as discoloration, difficult placement and frequent dislodgement due to their poor abrasion resistance make them less handy for use. Hence, they are contraindicated in cases with insufficient tooth surface for retention, severe bruxism, deep bite, crowding and excessive abrasion., ${ }^{2,46,10,12}$

\section{KUDOS CROWNS}

Kudos Crowns are newer generation of pediatric polycarbonate crowns which are flexible, easily adaptable needing less chair-side time., ${ }^{41}$ The crown can also be bonded to the tooth using either luting cement or composite after the acrylic relining. ${ }^{10,22}$

\section{DIRECT GROWN}

Direct Crown also supplies translucent pediatric polycarbonate crown shells for incisors and cuspids in 6 shades and 4 sizes- small, medium, large and x-large. ${ }^{23}$

\section{STRIP/CELLULOID CROWNS}

Strip crowns are prefabricated transparent celluloid crown forms that have been quite popular and widely used for a long time in pediatric dentistry. They were first introduced in 1979 by Webber and colleagues and described by Grosso F.C (1987). ${ }^{4}$ These crown forms are filled with composite resin and bonded to the teeth following which they are stripped off leaving behind a smooth surface., ${ }^{4,10}$ They offer superior esthetics with less chairside time and ease of repair. Studies show good parental satisfaction except for their slight concern regarding discoloration and durability. ${ }^{24}$ However, the placement requires adequate tooth structure and cooperative behavior in children in addition to the proper isolation that could otherwise have an adverse effect on bonding as well as the resin color. ${ }^{6,7,12}$ Though a technique sensitive procedure, studies have shown strip crowns placed under general anesthesia to have exhibited superior longevity owing to the absence of behavioral factors. ${ }^{25-27}$ Despite their popularity, the literature on their clinical efficacy are predominantly retrospective. ${ }^{10,24-25}$ Different materials have been explored for strip crown form to provide quality anterior restoration to marginally cooperative patients though the long term studies seem lacking. One such study by Margolis in 2002 suggested the use of resin modified glass ionomer (RMGI) cement as a dentin substitute in his sandwich technique of composite strip crown placement. ${ }^{28}$ Further, Nelson suggested the use of RMGI strip crowns ${ }^{29}$ while few others reported the use of resin bonded composite cement (RelyX Unicem) ${ }^{30}$ and bis-acryl composite-based temporization material (Luxatemp Star). ${ }^{31}$ Despite the ease and anticariogenic properties with RMGI strip crowns, they lack the required strength. ${ }^{4,10}$

\section{PEDO JACKET GROWNS}

Pedo jacket crowns offer ease in restoring carious maxillary primary anterior teeth especially in the precooperative age group. ${ }^{32}$ These soft and flexible jacket crowns are made of tooth colored copolyester materials which are bonded to the teeth. Advantages include easy trimming with scissors and minimal tooth reduction for multiple adjacent restorations. ${ }^{8,10}$ However, these are available in only one size and one very light shade making match for adjacent non-restored tooth difficult. These crowns should not be trimmed with a high speed finishing bur as the plastic coating melts to the bur. ${ }^{3}$ Further, discoloration, wear in areas of heavy occlusion and recurrent dislodgement are common problems cited with these esthetic restorations. ${ }^{2,6,9,12}$

\section{ACRYLIC GROWNS}

Custom made heat cured acrylic crowns can be another option for primary anterior full coverage restoration 
that provides good marginal adaptation and retention, especially in cases where there is space loss or inadequate tooth structure. Though it is cost-effective with no risk of discoloration, requirement of multiple sittings and laboratory work may be some of its drawbacks. ${ }^{33}$

\section{COMPOSITE BASED GROWNS/INDIREGT COMPOSITE RESIN GROWNS}

Indirect composite resin shell crowns are available as preformed crowns, custom made in laboratory and hand made on cast. New Millennium, Artglass, Pediatric Edelweiss, and Figaro crowns are few examples of preformed crowns having composite enhanced with glass fibers. Customized lab enhanced composite resin crowns offer high quality with more complete polymerization, better wear resistance, and decreased clinical chair-time as compared to the direct composite strip crowns. This technique entails a two-appointment procedure for tooth preparation and temporization on the first visit, followed by cementation on the second. However, long term studies validating its practicality and longevity are further required.

\section{NEW MILLENNIUM CROWNS/LIFE LIKE CROWNS}

New Millennium crowns are similar in form to the pedo jacket and strip crowns except that the jacket is made up of a laboratory-enhanced composite resin material. ${ }^{6}$ These are filled with resin material and bonded onto the teeth. ${ }^{2,9}$ These crowns can be finished and reshaped with excellent esthetics, but are brittle, expensive and require adequate moisture control. ${ }^{10,12}$

\section{ARTGLASS GROWNS (GLASTECH GROWNS/ ORGANIC GROWNS)}

Artglass crowns are preformed crowns made of indirect resin composites filled with polymer or organic glasses. These possess excellent esthetics and durability along with natural abrasion resistance and bondability of composite and porcelain. Other advantages include color stability, plaque resistance, ${ }^{6,12}$ fracture resistance and easy reparability. ${ }^{10}$ They are available in one shade and in six sizes. ${ }^{7}$ Failure of these crowns could be due to the inadequate bonding to the teeth. ${ }^{2,9}$

\section{INDIRECT CUSTOM MADE COMPOSITE RESIN/ SHELL CROWNS}

This is a novel technique where indirect composite resin crowns are built-up freehand on cast and then cemented onto the teeth. Prior to the composite build-up, double coating of separating media is applied to create a space for cementing media. This simple technique provides various advantages such as decreased operator technique-sensitivity, reduced chair-side time, decreased polymerization shrinkage and cementation of multiple anterior teeth simultaneously., ${ }^{4,8,10,34,35}$ Modification using silicone positioners for better alignment of multiple crowns during cementation have also been reported. ${ }^{35}$ Studies on this crown fabrication technique are relatively scarce. ${ }^{34,36}$

\section{ZIRCONIA CROWNS}

A recent addition to the spectrum of choices of prefabricated primary anterior crowns is the zirconia crowns. It was introduced by John P. Hansen and Jeffery P. Fisher in 2010. ${ }^{10}$ Sprig Oral Health Technologies (formerly EZ-pedo) were the first to provide zirconia crowns for children. ${ }^{10,37}$ These metal free prefabricated zirconia crowns though very expensive are widely popular nowadays. They are biocompatible and provide excellent esthetics with exceptional strength and durability. Since these crowns cannot be crimped, the retention is reliant mainly on cementation and their internal surface designs such as: internal retention bands in zirconia Kinder Krowns, zir-lock ultra grooves in EZ Pedo and crimp lock retentive design in Cheng crowns. Easy to place, fine operational skills must be observed while manipulating such crowns as trimming with high speed burs may lead to microcracks within the crown, forceful seating may lead to fracture and subgingival finish line may cause bleeding from gums hence, increasing the operatory time for placement. ${ }^{38}$ These crowns require more tooth reduction as passive fit of the crown is mandated.

There are four different commercially available zirconia crowns: NuSmile ZR, Zirconia Kinder Krowns, EZCrowns, and Cheng Crowns Zirconia. A recently published study reported highest parental satisfaction for zirconia crowns followed by resin composite strip crowns and then PVSSCs. ${ }^{39} \mathrm{NuSmile}$ zirconia crowns were proven to resist fracture even under intense pressure of load compared to the Cheng crowns zirconia. ${ }^{40}$

Conventional or self-adhesive resin cements have been recommended as luting agents for zirconia crowns. ${ }^{41,42}$ Recently, BioCem (NuSmile ${ }^{\circledR}$ ) is a bioactive, dual-cure RMGI which is light cured and releases phosphate, calcium as well as fluoride. BioCem cement had significantly less microleakage in zirconia prefabricated crowns. ${ }^{3,43}$ These bond very well to the SSCs and zirconia. ${ }^{3}$ 


\section{BIOLOGIC CROWNS}

Tavares in 1992 first described the technique of biological restoration in primary dentition. The use of biologic crown and post core restoration for maimed teeth has shown favorable results. The technique involves bonding sterile dental fragments to the teeth that have been derived either from the patient or tooth bank. Though the advantages of these crowns are provision of natural tooth-like esthetics, certain drawbacks such as availability of the acceptable tooth forms, rigorous sterilization and patient acceptance are some of the unsolved issues. , $^{9,10,44,45}$

\section{FIGARO GROWNS}

Recently introduced (2017) Figaro crowns have the potential to be a feasible option amongst many others. They are available in 5 sizes for each tooth and in universal style for lower incisors and composed of either fibreglass or quartz fibres/filaments embedded with an outer cosmetic composite resin material. These crowns are claimed to be the strongest among all, very easy to place, biocompatible and are autoclavable. In addition, these offer impeccable fit with their flex-fit technology and require very less tooth preparation similar to SSCs and hence less chair-side operatory time. ${ }^{4,46}$ Drawbacks with these crowns are that they cannot be crimped and also not clearly visible on the radiograph. ${ }^{47,48}$

\section{EDELWEISS PEDIATRIC CROWNS}

Introduced in 2018, Edelweiss pediatric crowns are the recent additions to the array of pediatric esthetic full coverage restorations. These are made of densely filled composite with layer-sintered barium glass and show great biocompatibility, natural abrasion behavior and easy reparability. These are available in small, medium and large sizes and offer sizing guides for easy selection of crowns. The crown needs slight roughening on the inside followed by etch and bond application and then bonded to the tooth with composite. However, these are expensive and yet to be clinically experimented. ${ }^{49}$

\section{DISINFEGTION AND STERILIZATION}

1. Chemical disinfection or cold sterilization using an aldehyde-free disinfectant in an ultrasonic bath. ${ }^{19,20,32}$ Preferred method for PVSSC, High density polyethylene veneered crowns, Polycarbonate crowns, Pedo Pearls and Pedo jacket crowns

2. Steam Autoclave SSCs, Zirconia crowns, Figaro crowns

\section{SUMMARY}

Multiple variety of preformed and custom-made pediatric anterior crowns have become available to pediatric dentists for restoring the children's smile, especially in this last decade. Qualities such as excellence in esthetics, durability and retention seem to be overlapping amongst these emerging crowns. The PVSSCs, zirconia and composite based crowns have added newer dimensions to the esthetic full coverage restorations for children. Nonetheless, the choice of crown depends on the preference and skill of the operator, behavior of the patient, occlusion, remaining tooth structure, parental expectations and affordability. However, more randomized clinical trials are encouraged to guide the clinicians in choosing appropriate anterior crowns for their dental practice.

Conflict of Interest: None

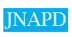

\section{REFERENGES}

1. Dave BH, Shah VU, Bargale S, Deshpande A, Patel R, Sura S. Evaluation of parental perception regarding smile of children according to visual analog scale. J Integr Health Sci 2018;6:41-4. [Full Text I DOI]

2. Yang JN, Mani G. Crowns for primary anterior teeth. Int J Pedod Rehabil. 2016;1(2):75-8. [Full Text | DOI]

Waggoner WF. Restoring primary anterior teeth: updated for 2014. Pediatr Dent. $2015 \mathrm{Mar}-\mathrm{Apr} ; 37(2): 163-70$. [PubMed]

B Amrutha. Tooth Coloured Crowns In Pediatric Dentistry- A Review. Int. J. Curr. Res. 2019;11(5):4098-104. [Full Text I DOI]

Christensen GJ. Clinician Report on Pediatric crowns are growing up: Reprint. 2012. Retrieved 4 October. Available from: https://www.cliniciansreport.org/uploads/ files/164/201211PedoCrowns.pdf. [Link]

6. Sahana S, Vasa AAK, Sekhar R. Esthetic crowns for primary teeth: a review. Ann. essences dent. 2010;2(2):87-93. [Full Text]

Lee JK. Restoration of primary anterior teeth: review of the literature. Pediatr Dent. 2002 Sep-Oct;24(5):506-10. [PubMed]

Garg V, Panda A, Shah J, Panchal P. Crowns in pediatric dentistry: A review. J Adv Med Dent Scie Res 2016;4(2):41-46. [Full Text]

Chadha T, Yadav G, Tripathi AM, Dhinsa K, Arora D. Recent trends of Esthetics in Pediatric Dentistry. Int J Oral Health Med Res 2017;4(4):70-75. [Full Text]

Babaji P. CROWNS IN PEDIATRIC DENTISTRY. First ed. New Delhi: Jaypee Publishers 2015. [Link]

1. Sahu AK, Patil RU, Kambalimath HV, Asokan A, Maran S, Jain S. Spectrum of choices to restore the smile of a child: An update on current pediatric anterior

crowns. J Dent Allied Sci 2016;5:25-9. [Full Text I DOI]

12. Mittal GK VA, Pahuja H, Agarwal S, Tomar H. Esthetic Crowns In Pediatric Dentistry: A review. Int JContemp Med Res 2016;3(5):1280-2. [Full Text] 
13. Oueis H, Atwan S, Pajtas B, Casamassimo PS. Use of anterior veneered stainless steel crowns by pediatric dentists. Pediatr Dent. 2010 Sep-Oct;32(5):413-6. [PubMed]

14. Kinder Krowns ${ }^{\circledR}$ - Pre-veneered Pediatric Crowns. Retreived 6 October 2020. Available from: https://www.kinderkrowns.com/pre-veneered-kinder-krowns/. [Link]

15. Shah PV, Lee JY, Wright JT. Clinical success and parental satisfaction with anterior preveneered primary stainless steel crowns. Pediatr Dent. 2004 SepOct;26(5):391-5. [PubMed]

16. Gupta M, Chen JW, Ontiveros JC. Veneer retention of preveneered primary stainless steel crowns after crimping. J Dent Child (Chic). 2008 Jan-Apr;75(1):447. [PubMed]

17. Guelmann M, Gehring DF, Turner C. Retention of veneered stainless steel crowns on replicated typodont primary incisors: an in vitro study. Pediatr Dent. 2003 May-Jun;25(3):275-8. [PubMed]

18. Flex white faced crowns- Space Maintainers Laboratories. Retreived 6 October 2020. Available from: https://www.smlglobal.com/flex-white-faced-crowns. [Link]

19. Yilmaz Y, Guler C. Evaluation of different sterilization and disinfection methods on commercially made preformed crowns. J Indian Soc Pedod Prev Dent. 2008 Dec;26(4):162-7. [PubMed I I

20. Wilson GM. High density polyethylene veneered crowns for children. Google Patents; 2000. Retreived 6 Ocober 2020. Available from: https:/patents.google.com/ patent/US6106295A/en. [Link]

21. Venkataraghavan K, Chan J, Karthik S. Polycarbonate crowns for primary teeth revisited: restorative options, technique and case reports. J Indian Soc Pedod Prev Dent. 2014 Apr-Jun;32(2):156-9. [PubMed I DOI]

22. Temporary pediatric crowns - Kudos crowns. Retreived 6 Ocober 2020. Available from: http://www.kudoscw.com.hk/product05.html. [Link]

23. Direct crown dental products- Temporary crowns. Retreived 6 Ocober 2020. Available from: https://www.directcrown.com/temporary. [Link]

24. Manmontri C, Sirinirund B, Langkapint W, Jiwanarom S, Kowan V, Tantayanusorn S, Nirunsittirat A. Retrospective Evaluation of the Clinical Outcomes and Patient and Parental Satisfaction with Resin Strip Crowns in Primary Incisors. Pediatr Dent. 2018 Nov 15;40(7):425-432. [PubMed]

25. Ram D, Fuks AB. Clinical performance of resin-bonded composite strip crowns in primary incisors: a retrospective study. Int J Paediatr Dent. 2006 Jan;16(1):4954. [PubMed I DOI]

26. Aiem E, Smaïl-Faugeron V, Muller-Bolla M. Aesthetic preformed paediatric crowns: systematic review. Int J Paediatr Dent. 2017 Jul;27(4):273-282. [라bMed I DOI]

27. Al-Eheideb AA, Herman NG. Outcomes of dental procedures performed on children under general anesthesia. J Clin Pediatr Dent. 2003 Winter;27(2):181-3. PubMed I DOI

28. Margolis FS. The sandwich technique and strip crowns: an esthetic restoration for primary incisors. Compend Contin Educ Dent. 2002 Dec;23(12):1165-9; quiz 1170. [PubMed]

29. Nelson T. An improved interim therapeutic restoration technique for management of anterior early childhood caries: report of two cases. Pediatr Dent. 2013 JulAug;35(4):124-8. [PubMed]

30. Jeong MA, Kim AH, Shim YS, An SY. Restoration of strip crown with a resin-bonded composite cement in early childhood caries. Case Rep Dent. 2013;2013:581934. [PubMed I DOI]

31. Gugnani N, Pandit IK, Gupta M, Nagpal J. Esthetic Rehabilitation of Primary Anterior Teeth using Temporization Material: A Novel Approach. Int J Clin Pediatr Dent. 2017 Jan-Mar;10(1):111-114. [PubMed I DOI]

32. Castro A, Badr SB, El-Badrawy W, Kulkarni G. Clinical Performance of Pedo Jacket Crowns in Maxillary Anterior Primary Teeth. J Dent Child (Chic). 2016 Sep 15;83(3):125-131. [PubMed]

33. Jathar P, Panse A, Desai AR. Acrylic crowns for esthetic rehabilitation of primary teeth. Int J Pedod Rehabil 2018;3(1):42-5. [Full Text I DOI]

34. Buch A, Shah S, Kariya PB, Keshan A. A cost-effective method of restoring primary anterior teeth with loss of crown structure. J Integr Health Sci 2018;6(1):31-3. Full Text I DOI]

35. Murthy PS, Deshmukh S. Indirect Composite Shell Crown: An Esthetic Restorative Option for Mutilated Primary Anterior Teeth. J. Adv. Oral Res. 2013;4(1):22-25. Full Text I DOI]

36. Motisuki C, Santos-Pinto L, Giro EM. Restoration of severely decayed primary incisors using indirect composite resin restoration technique. Int J Paediatr Dent. 2005 Jul;15(4):282-6. [PubMed IDOI]

37. EZCrowns. [Link]

38. Khatri A. Esthetic zirconia crown in Pedodontics. Int J Pedod Rehabil 2017;2:31-3. [Full Text I DOI]

39. Salami A, Walia T, Bashiri R. Comparison of Parental Satisfaction with Three Tooth-Colored Full-Coronal Restorations in Primary Maxillary Incisors. J Clin Pediatr Dent. 2015 Fall;39(5):423-8. [PubMed I DOI]

40. Al Shobber MZ, Alkhadra TA. Fracture resistance of different primary anterior esthetic crowns. Saudi Dent J. 2017 Oct;29(4):179-184. [PubMed I DOI]

41. Planells del Pozo P, Fuks AB. Zirconia crowns-an esthetic and resistant restorative alternative for ECC affected primary teeth. J Clin Pediatr Dent. 2014 Spring;38(3):193-5. [PubMed I DOI]

42. Karaca S, Ozbay G, Kargul B. Primary Zirconia Crown Restorations for Children with Early Childhood Caries. Acta Stomatol Croat. 2013;47(1):64-71. [DOI]

43. Stepp P, Morrow BR, Wells M, Tipton DA, Garcia-Godoy F. Microleakage of Cements in Prefabricated Zirconia Crowns. Pediatr Dent. 2018 Mar 15;40(2):136-139. [PubMed]

44. Md I, Singh Dhull K, Nandlal B, Kumar Ps P, Singh Dhull R. Biological restoration in pediatric dentistry: a brief insight. Int J Clin Pediatr Dent. 2014 SepDec;7(3):197-201. [PubMed I DOI]

45. N G, S R. Biological restorations: an alternative esthetic treatment for restoration of severely mutilated primary anterior teeth. Int J Clin Pediatr Dent. 2008 Sep;1(1):42-7. [PubMed I DOI]

46. Chakraborty S DA, Agarwala P, Zahir S, Lahiri PK, Kundu GK. Esthetic Rehabilitation Of Decayed Primary Incisors Using Figaro Crowns And Strip Crowns. IJDSIR. 2019;2(2):490-4. [Full Text]

47. Kavya KG, Anegundi RT, Tavargeri AK, Trasad V and Patil SB. An Update on Aesthetic Crowns. Austin J Dent. 2020; 7(3): 1143. [Full Text]

48. Figaro crowns. Retreived 6 Ocober 2020. Available from: https:/figarocrowns.com/. [Link]

49. Breakthrough in Pediatric Dentistry: Direct system Pediatric crowns- edelweiss dentistry. Retreived 6 Ocober 2020. Available from: https://www.edelweissdentistry. com/wp-content/uploads/2020/03/EW_PediatricCrown_Brochure_02_2020_EN_compressed.pdf. [Link] 